\title{
CARTAS DE CESARE PAVESE UMA CONFISSÃO DOS PECADOS
}

Furio Jesi

Comecei a ler o conjunto de cartas escritas por Cesare Pavese nos últimos seis anos de sua vida, procurando nelas, sobretudo, documentos que se referem à gênese da "Coleção de estudos religiosos, etnológicos e psicológicos", que me dissessem algo de novo sobre as relações entre Pavese e o mito. Os "velinos" de escritório que constituem a maior parte do epistolário 1945-50, agora recolhido em livro, deveriam, de fato, permitir reconstruir o trabalho de Pavese no tempo em que também decidiu imprimir seu trabalho editorial voltado à experiência do mito e do sagrado, transferindo, portanto, ao plano mais abertamente público e coletivo a revelação pessoal tida pela etnologia, pela ciência do mito e pela psicologia do profundo.

Entre os textos do primeiro ano, porém, detive-me numa carta muito secreta, enviada "a uma amiga", em 25 de novembro de 1945, que, talvez, ilumina a experiência religiosa e mitológica de Pavese, pelo menos no que diz respeito aos escritos em que ele falou explicitamente de rituais e de mitos. $\mathrm{Na}-$ quela carta, a palavra "mito" jamais aparece; ela é, muito mais, testemunho de uma experiência religiosa profunda e antiga, para a qual existe uma denominação clara: confissão dos pecados. A carta-confissão constitui uma categoria não rara das "cartas de amor", entre as quais poderia constar a carta de Pavese. Esta, no entanto, reconduz de modo particularmente evidente a confissãocarta de amor ao seu protótipo religioso, como autoacusação que determina a expulsão do pecado e é o pressuposto da regeneração.

$\mathrm{Na}$ carta de 25 de novembro de 1945, Pavese chega, além do mais, a elencar suas culpas numa espécie de tabela que poderia ser uma paródia da técnica de confissão católica; mas o tom do discurso mostra, sem equívocos, que a paródia foi reduzida pela angústia do agora à simples função de precedente

Lettere di Cesare Pavese: una confessione dei peccati.

Publicado pela primeira vez em Uomini e idee, Napoli, ano VIII, n. 5-6, set.-dic. 1966.

Posteriormente In: JESI, Furio. Letteratura e mito. Torino: Einaudi, 1968, p. 179-186.

Tradução de Davi Pessoa Carneiro. 
intelectual e estilístico: "Sinto vergonha de meu primo vendedor de tabaco", é uma das doze profissões de culpa. "Proponho-me não fazê-lo mais" é a proposição, retirada da linguagem católica tradicional, com que Pavese conclui as frases: "Brincando, certa vez, disse que sou católico - pois bem, isso é católico (ou cristão, se quiser). Crer nas almas alheias e respeitá-las. Fui violador, homicida, explorador, insidiador de almas alheias, mas sempre soube que fazia mal."

Uma situação análoga, em que a possível paródia da prática devota se transforma numa verdadeira e específica experiência religiosa que põe à parte o espírito paródico, aparece em outra "carta de amor" de Pavese, escrita em 17 de março de 1950 a Constance Dowling: "Nunca Ihe disse que quando jovem tive a superstição das 'boas ações'? Quando devia correr um perigo, fazer uma prova, por exemplo, estava atento naqueles dias a não ser mau, a não ofender ninguém, a não aumentar a voz, a não ter pensamentos ruins. Tudo isso para não afastar o destino de mim. Pois bem, aconteceu que nesses dias me tornei novamente rapaz e corro realmente um grande perigo, faço uma prova terrível, porque percebo que não ouso ser mau, ofender os outros, ter pensamentos vis. O pensamento em você e uma lembrança ou uma ideia indigna, ruim, não entram em comunhão."

Já na carta de 25 de novembro de 1945, advertia-se a mesma vontade de manter distantes da esfera das relações com a pessoa amada a impureza e a culpa: "Um dia the disse que 'diante de você jamais farei uma ação vil' e 'para vencer esse orgulho vou me enclausurar numa regra, onde controlarei especialmente os pensamentos." Da infância e do catolicismo era sobrevivida a noção de boa ação que permite merecer um êxito. Pavese, porém, mesmo recorrendo à linguagem convencional da devoção infantil, como vimos anteriormente, ("Proponho-me não fazê-lo mais", "não ter pensamentos ruins"), não pronuncia certas palavras mais precisas da linguagem católica: não diz "os meus pecados", mas "as minhas vergonhas", e mesmo quando evoca a experiência infantil afirma recorrer às boas ações "para não afastar o destino de [si]."

Essa última expressão, assim como a identificação do pecado com a "vergonha", busca evidentemente transferir a culpa, suas consequências e a confissão ao plano de uma experiência religiosa diferente daquela católica. Podemos suspeitar qual era o horizonte religioso desejado, caso façamos atenção a algumas expressões de Pavese, na carta de 25 de novembro de 1945, desti- 
nadas a ecoar com frequência em toda sua obra. Ao dizer aquilo que procurava para além da paixão, Pavese afirma: "A paixão foi sempre apenas uma condição colocada pelo meu orgulho, mas a intenção era outra. Era um valor objetivo, um bem. Que exprimia de novo, orgulhosamente, com as imagens de "carne e sangue", da monogamia, do absoluto, mas substancialmente queria dizer escolha de uma outra pessoa, materialidade e realidade dessa pessoa, primeiro passo para respeitá-la." E mais adiante: “... a necessidade de lhe enviar dinheiro, de lhe escrever, de entender por que sofre, de lhe doar sangue, quer o sangue da humilhação que de agora em diante procurarei como um frade?... Talvez tenha razão ao dizer que nunca encontrarei a carne e o sangue, mas errou ao dizer que não saberei tornar-me como você deseja."

Para Pavese, dizer "carne e sangue" é falar a linguagem do mito. As "brincadeiras" com que se encerram duas cartas ao agente literário Erich Linder (de $1^{\circ}$ de novembro de 1947 e de 11 de dezembro de 1948) deixam entrever um comportamento significativo de Pavese diante do material etnológico e do mito: "Em suma, esperemos esplêndidos livros e textos de etnologia, de psicanálise, de sangue e luxúria sacral". - "Que culpa eu tenho se finalmente me livrei dos Coralli... ${ }^{1}$ e não me ocupo senão de infâmias totêmicas e ancestrais?"

A revelação, nesse caso, é tanto mais significativa quanto mascarada pelo tom jocoso. A descida aos primórdios, inerente na experiência do mito e no abandono ao fluxo mitológico, era, portanto, uma tomada de contato com "sangue e luxúria sacral", "infâmias totêmicas e ancestrais". A "revelação" da etnologia havia aberto a Pavese uma esfera capaz de oferecer satisfação à sua pesquisa de "carne e sangue" no mesmo âmbito religioso em que - como atesta a carta de 25 de novembro de 1945 - ele queria reconduzi-la à essência (e em 14 de julho de 1949, ele escreve uma resposta a Rosa Calzecchi Onesti, a qual "via em Pavese um tormento religioso, e lhe desejava que encontrasse solução para o mesmo": "Quanto à solução que desejava que encontrasse, acredito que dificilmente irei além do cap. XV do Gallo. De todo modo, não se enganou sentindo que esse é o ponto inflamado, o locus de toda a minha consciência"). Mas definir essa pesquisa na esfera do sagrado não significava suscitar novamente uma componente insuprimível da experiência religiosa de Pavese (Kerényi diria "de seu estilo religioso"), ou seja, a noção da culpa e a adesão profunda ao ritual da confissão. "Sangue e luxúria sacral"

\footnotetext{
${ }^{1}$ Em 1947, Cesare Pavese inaugura a coleção "Coralli", na editora Einaudi, com o objetivo de publicar novos escritores italianos e estrangeiros. (n. t.)
} 
eram para Pavese realidades verdadeiras e por si mesmas regeneradoras, mas também "infâmias totêmicas e ancestrais". Se o pecado do orgulho, do qual ele se acusa na carta de 25 de novembro de 1945, levava-o a acreditar poder atingir a força regeneradora do sangue e da orgia primordial, a consciência da própria culpa o levava a se submeter a uma regra severa de comportamento, a um constante sacrifício de si, que, para serem realizados, deviam se fundar, antes de tudo, na confissão. Tal confissão teria sido, como na carta de 25 de novembro, acusação de suas "vergonhas", mas também denúncia do pecado do orgulho que o induzia a acreditar poder encontrar "carne e sangue".

Resta, no entanto, esclarecer por que "carne e sangue", "sangue e luxúria sacral”, eram, em algum modo, "infâmias". A explicação, além do mais, parece implícita na mesma admissão: "Talvez você tenha razão ao dizer que jamais encontrarei a carne e o sangue". Assim como em Bella estate, o tempo mítico de festa só sobrevive como aparência profanada, também a "carne e o sangue" se tornaram inalcançáveis. O acesso coletivo ao mito está perdido, e um acesso solitário é intrinsecamente deformante e culpado. Assim, "sangue e luxúria sacral", por si mesmos puros e regeneradores para quem os acolhia nas experiências míticas coletivas do passado, tornaram-se "infâmias" para quem comete o pecado do orgulho, esperando alcançá-lo, hoje, em solidão.

Diante desses mitos profanados se impõe na experiência religiosa de $\mathrm{Pa}$ vese o mito genuíno e intacto do sacrifício, do dever, do necessário e consciente adequar-se a uma lei que conduz à morte. "Quero bem a minha irmã escreve Pavese sempre na carta de 25 de novembro - porque se levanta todos os dias de madrugada e vai até a igreja e não crê, mas se abandona por um momento e depois é como um dever, uma coisa rígida e justa que é feita". Para ele o dever não é "ir até a igreja", mas o sacrifício de trabalhar, de escrever, de queimar os próprios mitos, de dar testemunho de uma lei totalmente obscura, não salvífica, mas fatal, que impõe a norma moral e exigirá como último sacrifício a morte.

Se agora examinamos os volumes da "Coleção de estudos religiosos, etnológicos e psicológicos" publicados durante a vida Pavese, ou por ele projetados, percebemos uma série de ambiguidades que são confirmadas pela correspondência daqueles anos, e que nossas considerações precedentes lançam uma luz especial. Pavese, de fato, a partir de um certo momento dedicou a maior parte de seu ofício editorial à publicação de textos cuja escolha, do ponto de vista científico, pode ser acusada de ecletismo e também de diletan- 
tismo, mas que evidentemente era justificada por encontrar Pavese em cada volume - embora em medidas diversas - "sangue e luxúria sacral" (é muito significativo, além do mais, que Pavese escrevesse, no dia 18 de outubro de 1947, a Luciano Foà, o qual propunha novas obras para a coleção: "Perceba que mais do que o antigo Oriente e as mandalas, interessa-nos a verdadeira etnologia, ou boa psicanálise"). Por razões aparentemente opostas, Ernesto De Martino (que quis, depois, reduzir ao mínimo sua responsabilidade na escolha dos textos, e se reprovou "por não ter visto então com clareza a inoportunidade"), colocando todos no mesmo saco, acusando de "irracionalismo" quinze das vinte obras da coleção, acolhendo na culpa Frobenius, Kerényi, Jung, Lévy-Bruhl, Eliade, etc. De Martino via empenhados em áspera polêmica "irracionalismo" e "historicidade", e ao definir uma única fronte de adversários reconhecia implicitamente - e de modo muito discutível - validez científica e organicidade na escolha de Pavese (para ele também reprovável). Ele, porém, tinha ao menos razão ao observar que Pavese encontrou um denominador comum em todas aquelas obras disparatadas: o denominador, de fato, era: "sangue e luxúria sacral".

A maior parte dos textos da coleção é precedida por uma introdução crítica, e muitas das introduções foram redigidas antes da morte de Pavese. Elas deixam precisamente uma impressão de ambiguidade, se não de contradição, tornada mais grave pelo pensamento de que o próprio Pavese as "deliberou para a impressão". Protótipo de tais introduções é aquela escrita por Ranuccio Bianchi Bandinelli para a Kulturgeschichte Afrikas [História da civilização africana], de Leo Frobenius: uma introdução violentamente polêmica nos confrontos da obra de Frobenius, tanto que não poupou os golpes voltados a tudo aquilo que era suspeito de irracionalismo, dados pelo próprio Frobenius ("chega-se, num passo, ao racismo de Rosenberg") a Heidegger, a Henry Miller, a Sartre, às “teorizações do moderno 'abstracionismo' nas artes figurativas, descendo até as mais desfeitas experiências contemporâneas que, com a recusa, de fato, de todo elemento racional, teorizam o retorno ao abandono infantil (dadá, etc.) e a arte automática, ou seja, as formas traçadas inconscientemente pelo pincel imbuído de cor (como se vê nos estudos à la page da $57^{\text {a }}$ rua leste de Nova York, especialmente depois de abundantes oferendas)". Citamos essa passagem simplesmente para colocar em evidência a violência e a vontade deliberada de envolver na mesma acusação toda suspeita de irracionalismo. Bianchi Bandinelli insiste, sobretudo, em destacar o caráter de 
dom perigoso oferecido por Pavese à cultura italiana, publicando a obra de Frobenius, e se preocupa em oferecer na abertura do volume aquilo que lhe parece o antídoto indispensável. A carta com que Pavese anunciou a Bianchi Bandinelli a publicação da obra nos deixa, portanto, muito desconcertados, mesmo se quisermos descobrir nela uma certa ambiguidade e uma cortesia indispensável: "Caro Bandinelli, o livro de Frobenius acabou de sair e acredito que você o recebeu. Parece-me uma boa contribuição à coleção, especialmente por mérito seu" (21 de abril de 1950).

Parece-nos lícito, porém, para encontrar de algum modo reparo naquele desconcerto e descobrir a coerência mais secreta do comportamento de $\mathrm{Pa}$ vese, recorrer às nossas hipóteses precedentes. O Pavese que aprovou o prefácio de Bianchi Bandinelli para o livro de Frobenius (e que já havia escrito a Giuseppe Cocchiara: "Cogni, iremos puni-lo com um prefácio de R. Bianchi Bandinelli para o livro de Frobenius, onde se tocará no nazismo") era provavelmente aquele mesmo que mascarava sua sensação de culpa diante do "sangue e luxúria sacral". A partir desse ponto de vista a mesma "Coleção de estudos religiosos, etnológicos e psicológicos" é o símbolo da tentação e da confissão: confissão e acusação ao propor à cultura italiana "sangue e luxúria sacral" transformados em "infâmias" inacessíveis coletivamente, confiança talvez - no antídoto fornecido pelo aparato científico e pela aberta requisitória de prefácio como aquele de Bianchi Bandinelli. Aquele mesmo Pavese que recusava adesão à narrativa fantástica e que repreendia Maria Cristina Pinelli: "Fique atenta, porque escapando da realidade com bruxas, anões e encantamentos, joga-se o jogo daqueles senhores que já se alastraram nos vinte anos de fascismo" (15 de abril de 1947), considera, talvez, pessoalmente necessário reduzir seu ofício de editor de livros numa grande confissão dos pecados. A parte assumida por Pavese na polêmica "historicidade-irracionalismo", e sua réplica a Fortini sobre o primeiro número da revista Cultura e realtà, de 1950, deixam as coisas no mesmo ponto, pois novamente Pavese mostra unir num único substrato "sangue e luxúria sacral", isto é, tudo aquilo que seus adversários chamam de "irracionalismo": "Ao contrário, é necessário temer que do mito, da magia, da 'participação mística', o estudioso 'científico' esqueça a característica mais importante: o valor absoluto cognitivo que eles representam, sua originalidade histórica, sua vitalidade perene na esfera do espírito". ${ }^{2}$ No fundo do denominador comum que Pavese reconhecia no mito,

\footnotetext{
${ }^{2}$ Cultura e realtà, Roma, n. 1, 1950.
} 
na magia, na participação mística, também havia sempre aquela noção de culpa, sanável não só pela confissão, mas, sobretudo, pela experiência do último mito sobrevivido genuíno aos seus olhos: o mito do sacrifício à lei obscura que impõe a moral, o dever, a morte. Essa lei atinge a coletividade, mas sua mais nítida epifania aparece no indivíduo e quando ele se abandona pode Ihe parecer o seu destino: "Agora é o inverso: sei que a vida é incrível, e que essa é uma tragédia fútil, como ter diabetes ou câncer por causa do cigarro" (carta "a uma jovem", agosto de 1950). 